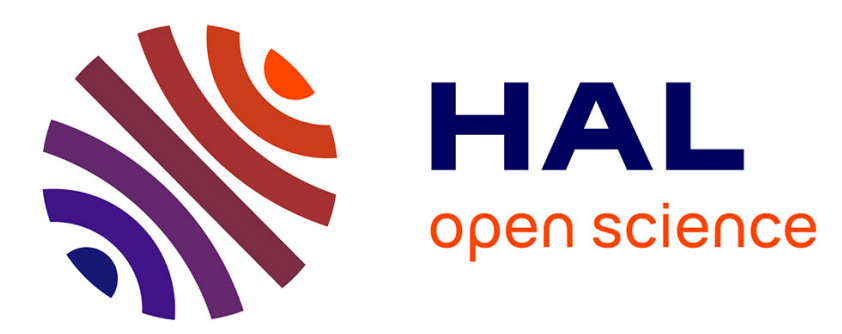

\title{
Dynamic relaxations in a bio-based polyamide with enhanced mechanical modulus
}

Geoffrey Haddou, Aurélien Roggero, Jany Dandurand, Eric Dantras, Philippe Ponteins, Colette Lacabanne

\section{- To cite this version:}

Geoffrey Haddou, Aurélien Roggero, Jany Dandurand, Eric Dantras, Philippe Ponteins, et al.. Dynamic relaxations in a bio-based polyamide with enhanced mechanical modulus. Journal of Applied Polymer Science, 2018, 135 (47), pp.1-6. 10.1002/APP.46846 . hal-01962043

\section{HAL Id: hal-01962043 https://hal.science/hal-01962043}

Submitted on 20 Dec 2018

HAL is a multi-disciplinary open access archive for the deposit and dissemination of scientific research documents, whether they are published or not. The documents may come from teaching and research institutions in France or abroad, or from public or private research centers.
L'archive ouverte pluridisciplinaire HAL, est destinée au dépôt et à la diffusion de documents scientifiques de niveau recherche, publiés ou non, émanant des établissements d'enseignement et de recherche français ou étrangers, des laboratoires publics ou privés. 


\section{Open Archive Toulouse Archive Ouverte (OATAO)}

OATAO is an open access repository that collects the work of Toulouse researchers and makes it freely available over the web where possible

This is an author's version published in: http://oatao.univ-toulouse.fr/ 20884

Official URL: https://doi.org/10.1002/APP.46846

\section{To cite this version:}

Haddou, Geoffrey Jany Colette Dynamic relaxations in a bio-based polyamide with enhanced mechanical modulus. (2018) Journal of Applied Polymer Science, 135 (47). 1-6. ISSN 0021-8995

Any correspondence concerning this service should be sent to the repository administrator: tech-oatao@listes-diff.inp-toulouse.fr 


\title{
Dynamic relaxations in a bio-based polyamide with enhanced mechanical modulus
}

\author{
G. Haddou, ${ }^{1,2}$ A. Roggero, ${ }^{2}$ J. Dandurand, ${ }^{2}$ E. Dantras $\mathbb{1}^{1}{ }^{2}$ P. Ponteins, ${ }^{1}$ C. Lacabanne ${ }^{2}$ \\ ${ }^{1}$ Assystem Toulouse, 31 300, Toulouse, France \\ ${ }^{2}$ CIRIMAT, Université de Toulouse, Physique des Polymères, 31062, Toulouse Cedex 09, France \\ Correspondence to: E. Dantras (E-mail: eric.dantras@univ-tlse3.fr)
}

\begin{abstract}
A new grade of bio-based polyamide (PA) - PA meta-xylylene diamine 10 (PA mXD 10)-was investigated. Its first interest is that it permits mild processing conditions at about $200{ }^{\circ} \mathrm{C}$. The calorimetric study shows the existence of two cold crystallizations indicative of slow crystallization rate. The glass transition stabilizes at $55{ }^{\circ} \mathrm{C}$. By combining calorimetry with dynamic mechanical analysis and dynamic dielectric spectroscopy, we found a perfect consistency between the set of data giving the molecular mobility. The localized relaxations follow Arrhenius equations while the viscoelastic transition follows a Vogel-Fulcher-Tammann law. The compilation of all the relaxation times determined by means of the different analyses highlights a good correlation. This result is perfectly explained by the polarity of the macromolecular chain. The dynamic mechanical behavior showed a storage modulus higher than for the corresponding aliphatic PA and nearly constant until room temperature. () 2018 Wiley Periodicals, Inc. J. Appl. Polym. Sci. 2018, $135,46846$.
\end{abstract}

KEYWORDS: dielectric properties; differential scanning calorimetry; mechanical properties; polyamides; thermoplastics

DOI: $10.1002 / a p p .46846$

\section{INTRODUCTION}

Aliphatic polyamides (PAs) are known since decades as engineering polymers due to the presence of hydrogen bonds: the most known are PA 6,6 and PA $6 .{ }^{1-7}$ Such polymers are well known for their processability even if they require high temperatures. The main drawback of these PA is the water sensitivity. ${ }^{8-11}$ The sorption of water molecules leads to a plasticization of the glass transition and the decrease of mechanical properties. By increasing the length of aliphatic sequences, the water uptake was limited and mild processing conditions are obtained. ${ }^{12,13}$ PA 11 and PA 12 were developed along those lines. ${ }^{14-17}$

In parallel, the development of aromatic PAs is sustained by very attractive applications as thermostable polymers. ${ }^{18-22}$ For a better processing in industrial conditions, semi-aromatic PAs were designed. $^{18,23,24}$

In the last decade, a lot of research was devoted to bio-based PAs. ${ }^{25-29}$ The strategy is to enhance the mechanical properties of classical bio-based PAs like PA 11. Following this line, Arkema proposed the PA meta-xylylene diamine 10 (PA mXD 10). ${ }^{30}$ This PA is constituted by an alternation of a phenyl ring and an aliphatic sequence in order to reach technical mechanical properties and mild processing temperature. In a first part of this study, the thermal behavior of PA mXD 10 is investigated by differential scanning calorimetry. Then, the investigations focus mainly on the molecular mobility of PA mXD 10 under mechanical and dielectric solicitations. The influence of hydration on the relaxation modes is shown. The combination of calorimetric, mechanical, and dielectric analyses will allow us to determine the molecular origin of the dynamic behavior of PA mXD 10.

\section{EXPERIMENTAL}

\section{Materials}

PA mXD 10 is a semicrystalline thermoplastic supplied by Arkema (France). Its structure is illustrated in Figure 1.

As received pellets of $\mathrm{PA} \mathrm{mXD} 10$ were hot pressed at $210^{\circ} \mathrm{C}$, $10 \mathrm{MPa}$ for $15 \mathrm{~min}$. Two aluminum plates were used to obtain a homogeneous thickness of the film thanks to the flexibility of the polymeric chain. The dimensions of the samples depend on the test to perform as follows:

- for calorimetric tests, the samples (about $12 \mathrm{mg}$ ) were extracted from a film of PA mXD 10,

- for mechanical tests, rectangular parallelepipeds about $50 \mathrm{~mm} \times 10 \mathrm{~mm} \times 0.65 \mathrm{~mm}$ were directly processed into a mold with good dimensions,

- for dielectric analyses, disks with a diameter about $40 \mathrm{~mm}$ and a thickness around $0.1 \mathrm{~mm}$ were extracted from the same disk than the calorimetric samples. 


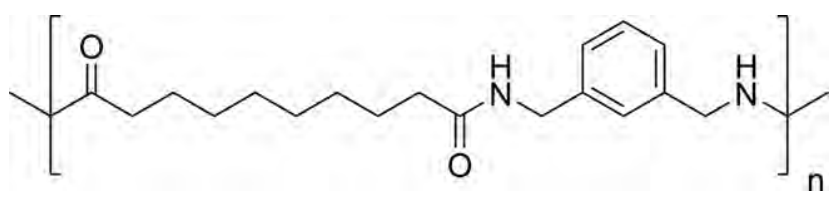

Figure 1. Structure of the PA mXD 10.

Differential scanning calorimetry (DSC), dynamic mechanical thermal analyses (DMA), and dynamic dielectric spectroscopy (DDS) data presented in the manuscript are the compilation of results recorded on six different samples. During the first heating, the water content of PA $\mathrm{mXD} 10$, as determined from water sorption experiments, was $1.3 \% \pm 0.2 \%$. During the second consecutive heating, it is $0 \%$ due to evaporation.

\section{Methods}

Differential Scanning Calorimetry. DSC was performed on a Diamond DSC (Perkin Elmer, Massachusetts, USA ). The samples were placed in closed aluminum pans. They were characterized, under helium atmosphere allowing to reach the lower temperature, in the range $0-250{ }^{\circ} \mathrm{C}$, at $10^{\circ} \mathrm{C} \mathrm{min}{ }^{-1}$, in order to erase the thermal history of the polymer. Then, they were cooled from 250 to $0{ }^{\circ} \mathrm{C}$ at $10{ }^{\circ} \mathrm{C} \mathrm{min}{ }^{-1}$, in order to crystallize the polymer. Finally, the samples were heated a second time, immediately after cooling, to determine the influence of the water evaporation.

Dynamic Mechanical Thermal Analysis. DMA were performed using an Advanced Rheometric Expansion System set up (Rheometric Scientific, USA). The measurements were performed in the rectangular torsional mode, from -140 to $150{ }^{\circ} \mathrm{C}$, with a heating rate of $3{ }^{\circ} \mathrm{C} \mathrm{min}^{-1}$, under nitrogen flow, at a frequency of $1 \mathrm{rad} \mathrm{s}^{-1}$, with a dynamic shear strain of $0.1 \%$. The complex shear modulus $G^{*}$ is defined by eq. (1)

$$
G^{*}(\omega, T)=G^{\prime}(\omega, T)+i G^{\prime \prime}(\omega, T)
$$

where $G^{\prime}$ is the storage modulus and $G^{\prime \prime}$ is the loss modulus.

Dynamic Dielectric Spectroscopy. DDS was made on an impedance analyzer BDS 4000 (Novocontrol technologies $\mathrm{GmbH}$ \& Co., Germany). The samples were placed between gold-plated stainless steel electrodes $(\varnothing=40 \mathrm{~mm})$. The measures were performed isothermally from -150 to $150{ }^{\circ} \mathrm{C}$, with a step of $5{ }^{\circ} \mathrm{C}$, in a frequency range from $10^{-2} \mathrm{~Hz}$ to $10^{6} \mathrm{~Hz}$. The complex permittivity $\varepsilon^{*}$ is calculated from the measurement of the complex impedance $Z^{*}$ according to eq. (2)

$$
\varepsilon^{*}(\omega, T)=\varepsilon^{\prime}(\omega, T)-i \varepsilon^{\prime \prime}(\omega, T)=\frac{1}{i \omega C_{0} Z^{*}(\omega, T)}
$$

where $\varepsilon^{\prime}$ and $\varepsilon^{\prime \prime}$ are, respectively, the real component and the imaginary component of the dielectric permittivity.

\section{RESULTS AND DISCUSSION}

\section{Calorimetric Behavior}

Consecutive scans of PA mXD 10 are represented in Figure 2. In the first scan, the curve reveals four events: a step at $35{ }^{\circ} \mathrm{C}$ related to the glass transition temperature $T_{g}$ with a superimposed endothermic peak which is the manifestation of the physical ageing; two exothermic peaks $T_{c 1}$ and $T_{c 2}$, at $78^{\circ} \mathrm{C}$ and $106^{\circ} \mathrm{C}$,

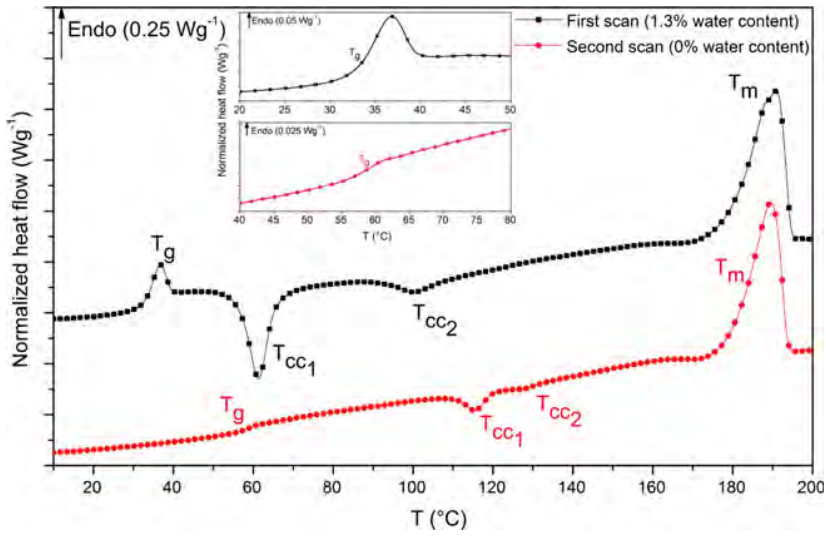

Figure 2. DSC curves of PA mXD 10. A zoom-in of the glass transitions for each heating id reported in the insert. [Color figure can be viewed at wileyonlinelibrary.com]

associated with cold crystallizations of crystallites with different morphologies; and only one wide melting point $T_{m}$ at $189{ }^{\circ} \mathrm{C}$. The different crystallites melt at close temperature. For the second scan, the glass transition is shifted to $58^{\circ} \mathrm{C}$. Since the thermal history was erased, there is no physical ageing superimposed onto the $T_{g}$ step. The polymer absorbed water molecules due to the presence of hydrophilic amide groups. It is well known that water plasticized the PAs. ${ }^{2,4,9-11}$ At room humidity, the water uptake is $1.3 \% \pm 0.2 \% \mathrm{wt}$ that is enough to influence the molecular mobility of the amorphous phase. Moreover, the cold crystallizations are shifted toward higher temperatures. This shift can be attributed to the drying of the sample. The significant decrease of the magnitude of the cold crystallization peak indicates that the sample is not fully crystallized due to a cooling faster than the crystallization kinetic of PA mXD 10. This effect on the crystallization kinetic may be attributed to the presence of the aromatic ring on the main chains. The melting temperature is unmodified but the melting peak is thinner and an exothermic event occurs before the peak. This phenomenon is related to the melting/reorganization/recrystallization phenomenon. ${ }^{12,31,32}$ All the data are indexed in Table I. The crystalline ratio was determined according to eq. (3).

$$
\chi(\%)=\frac{\Delta H_{m}-\sum \Delta H_{\mathrm{cc}}}{\Delta H_{\infty}}
$$

where $\chi$ is the crystallinity ratio, $\Delta H_{m}$ is the measured melting enthalpy, $\Sigma \Delta H_{\mathrm{cc}}$ is the sum of measured enthalpies of the cold crystallizations, and $\Delta H_{\infty}$ is the theoretical melting enthalpy of $100 \%$ crystallized polymer. The value used here is $244 \mathrm{~J} \mathrm{~g}^{-1}$ which is the enthalpy of $100 \%$ crystallized PA $11 .^{33}$ This value was chosen due to the close structures between PA 11 and PA $\mathrm{mXD}$ 10. Moreover, this is a comparative investigation, not a quantitative one, so the error is negligible. In this study, the crystallinity was calculated about $9 \%$ for the first scan and $12 \%$ for the second. This difference is due to a cooling after processing faster than the one employed here $\left(10^{\circ} \mathrm{C} \mathrm{min}^{-1}\right)$.

The $T_{g} / T_{m}$ ratio was calculated and is about 0.7 . This result is consistent with the van Krevelen relation valid for a majority of unsymmetrical polymers. ${ }^{34}$ 
Table I. Thermal Characteristics of PA mXD $10^{\mathrm{a}}$

\begin{tabular}{lccccccccc}
\hline Scan & $T_{g}\left({ }^{\circ} \mathrm{C}\right)$ & $T_{\mathrm{cc} 1}\left({ }^{\circ} \mathrm{C}\right)$ & $\Delta H_{\mathrm{cc} 1}\left(\mathrm{~J} \mathrm{~g}^{-1}\right)$ & $T_{\mathrm{cc} 2}\left({ }^{\circ} \mathrm{C}\right)$ & $\Delta H_{\mathrm{cc} 2}\left(\mathrm{~J} \mathrm{~g}^{-1}\right)$ & $T_{m}\left({ }^{\circ} \mathrm{C}\right)$ & $\Delta H_{m}\left(\mathrm{~J} \mathrm{~g}^{-1}\right)$ & $\chi(\%)$ & $T_{g} / T_{m}$ ratio \\
\hline 1st & $37(3)$ & $62(2)$ & $-17.52(0.03)$ & $122(5)$ & $-7.77(0.08)$ & $188(2)$ & $48.08(0.03)$ & $9.34(0.05)$ & $0.672(0.009)$ \\
2nd & $55(2)$ & $111(1)$ & $-8.23(0.01)$ & $127(3)$ & $-4.6(0.1)$ & $189(2)$ & $42.11(0.02)$ & $12.00(0.05)$ & $0.710(0.007)$ \\
\hline
\end{tabular}

a Standard deviations are between brackets.

\section{Mechanical Behavior}

Figure 3 shows the different components of the complex shear modulus $G^{*}(\omega)$ recorded at $1 \mathrm{~Hz}$, as a function of temperature: The storage modulus $G^{\prime}$, in filled symbols, and the loss modulus $G^{\prime \prime}$, open symbols. At $1.3 \%$ water content, at low temperature, there is a feeble step at $-83{ }^{\circ} \mathrm{C}$ on the storage modulus. This step is the $\beta_{2}$ relaxation, associated with the amide-water interactions. At $39^{\circ} \mathrm{C}$, there is a sharp step. This relaxation, called $\alpha$ relaxation, is related to the mechanical manifestation of the glass transition, which is consistent with the calorimetric results. These relaxations are typical of the polymers from PA family., $2,9,35,36$ Beyond the $\alpha$ relaxation, the storage modulus increases. Occurring at $72{ }^{\circ} \mathrm{C}$, this improvement is the expression of the cold crystallization.

After drying, the relaxations are significantly modified. The $\alpha$ relaxation is shifted toward $60{ }^{\circ} \mathrm{C}$. As observed by DSC, this improvement can be explained by the water desorption during the first scan. The $\beta_{2}$ relaxation disappears and another weak and wide relaxation appears at $-58{ }^{\circ} \mathrm{C}$. This component noted $\beta_{1}{ }^{9,37}$ is usually highlighted for the dried specimens of PA and is associated with the amide-amide interactions. The $\beta_{1}$ relaxation is hidden by the $\beta_{2}$ mode, in the presence of water molecules.

The temperature dependence of the dynamic mechanical modulus of PA mXD 10 is analogous with the one of PA 11. For both polymers, the viscoelastic region occurs around $50{ }^{\circ} \mathrm{C}$ so that both are glassy below this temperature and rubbery above this temperature. For the glassy state, the storage modulus (glassy modulus) has been measured at $0{ }^{\circ} \mathrm{C}$ : it is about $1.32 \mathrm{GPa}$ for PA

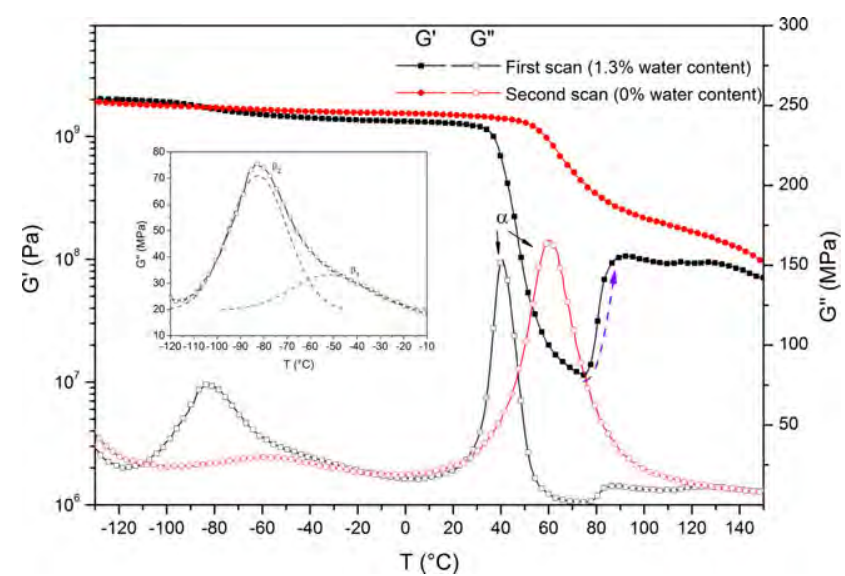

Figure 3. First and second DMA scans of PA mXD 10 at $1 \mathrm{rad} \mathrm{s}^{-1}$. The filled symbols represent the storage modulus $G^{\prime}$ and the empty symbols the loss modulus $G^{\prime \prime}$. A zoom-in of the $\beta_{1}$ and $\beta_{2}$ relaxations is reported in the insert. [Color figure can be viewed at wileyonlinelibrary.com]
$\mathrm{mXD} 10$, instead of $0.53 \mathrm{GPa}$ for PA 11 . For the rubbery state, the storage modulus (rubbery modulus) has been recorded at $100{ }^{\circ} \mathrm{C}$, it is $0.22 \mathrm{GPa}$ for PA mXD 10 instead of $0.09 \mathrm{GPa}$ for $\mathrm{PA} 11 .^{38}$ It is important to note that the storage modulus is higher for PA mXD 10 than for PA11 in the whole temperature range. This increase is a classical consequence of the introduction of the phenylene groups on the PA chain. The challenge was to optimize the conservative modulus without any increase of transition temperatures.

\section{Dielectric Behavior}

The dielectric loss after Kramers-Kronig transform is represented in Figure 4, for the samples at $1.3 \%$ water content. The KramersKronig transform allows us to suppress the ohmic conduction which can hide the dielectric relaxations. In Figure 4, three events are observed in addition to the relaxations previously observed in DMA. At the lowest temperature, the $\gamma$ relaxation is observed: this relaxation is associated with the mobility of the ethylene sequences between two polar groups. ${ }^{2,35}$ Above the $\alpha$ relaxation, the Maxwell-Wagner-Sillars (MWS) phenomenon is related to heterogeneities induced by crystalline/amorphous interfaces. ${ }^{39}$ At highest temperature and lowest frequency, the dielectric loss greatly increases due to the conduction front labeled $\sigma$.

For a better understanding of the relaxation evolution, the mean relaxation times were determined thanks to the HavriliakNegami equation, defined by eq. (4)

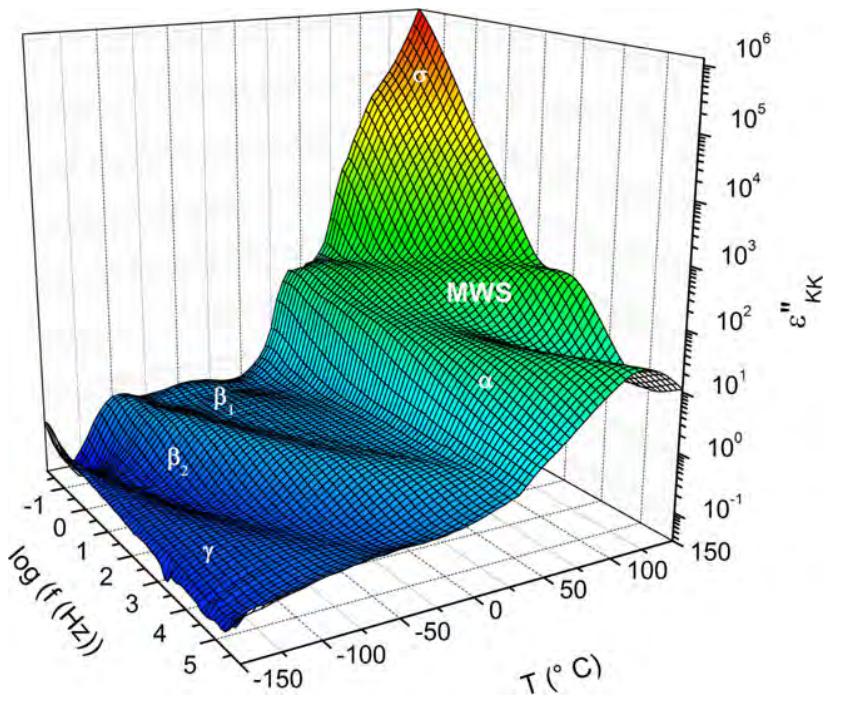

Figure 4. 3D spectrum of dielectric loss versus frequency and temperature after Kramers-Kronig transform at $1.3 \%$ water content. [Color figure can be viewed at wileyonlinelibrary.com] 


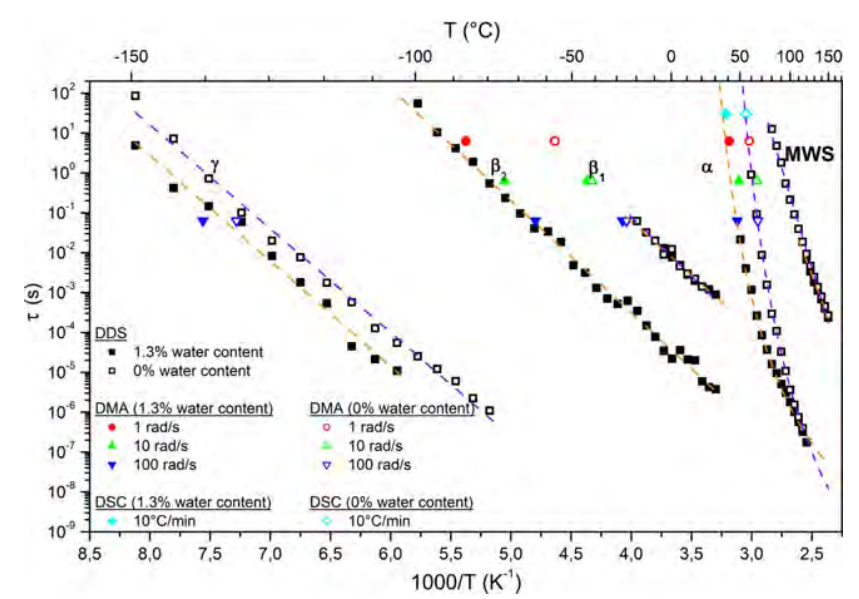

Figure 5. Arrhenius plot of relaxation times of PA mXD 10 at $0 \%$ and $1.3 \%$ water content. (the dashed lines represent the Arrhenius and VFT fits). [Color figure can be viewed at wileyonlinelibrary.com]

$$
\varepsilon^{*}=\varepsilon_{\infty}+\frac{\varepsilon_{S}-\varepsilon_{\infty}}{\left(1+\left(i \omega \tau_{\mathrm{HN}}\right)^{\alpha_{\mathrm{HN}}}\right)^{\beta_{\mathrm{HN}}}}
$$

where $\varepsilon_{\infty}$ is the high-frequency limit of the relative real permittivity, $\epsilon_{S}$ is the low-frequency limit of the relative real permittivity, $\omega$ is the angular frequency and $\alpha_{\mathrm{HN}}$ and $\beta_{\mathrm{HN}}$ are the Havriliak-Negami fit parameters, respectively related to the width and the symmetry of the distribution.

All the relaxation times are plotted on the Arrhenius diagram in Figure 5. The localized modes $\gamma, \beta_{1}$, and $\beta_{2}$ have an Arrhenius behavior described by eq. (5)

$$
\tau(T)=\tau_{0 a} e^{\frac{E_{a}}{R T}}
$$

where $\tau_{0 a}$ is the pre-exponential factor, $\Delta H$ is the activation enthalpy, $R$ is the gas constant.

The $\alpha$ relaxation follows the Vogel-Fulcher-Tammann (VFT) behavior described by eq. (6).

$$
\tau(T)=\tau_{0 v} e^{\frac{1}{\alpha_{f}\left(T-T_{\infty}\right)}}
$$

where $\tau_{0 v}$ is the pre-exponential factor, $\alpha_{f}$ is the free volume thermal expansion coefficient, and $T_{\infty}$ is the Vogel temperature.

\begin{tabular}{|c|c|c|c|c|}
\hline \multirow[b]{2}{*}{$\begin{array}{l}\text { Dielectric } \\
\text { phenomena }\end{array}$} & \multicolumn{2}{|c|}{$\begin{array}{c}1.3 \% \\
\text { water content }\end{array}$} & \multicolumn{2}{|c|}{$\begin{array}{c}0 \% \\
\text { water content }\end{array}$} \\
\hline & $\begin{array}{c}E_{a} \\
\left(\mathrm{~kJ} \mathrm{~mol}^{-1}\right)\end{array}$ & $\tau_{\mathrm{Oa}}(\mathrm{s})$ & $\begin{array}{c}E_{a} \\
\left(\mathrm{~kJ} \mathrm{~mol}^{-1}\right)\end{array}$ & $\tau_{\mathrm{Oa}}(\mathrm{s})$ \\
\hline$\gamma$ & $50(1)$ & $1.9 \times 10^{-21}$ & $49(2)$ & $5.5 \times 10^{-20}$ \\
\hline$\beta_{2}$ & $54(1)$ & $1.1 \times 10^{-15}$ & - & - \\
\hline$\beta_{1}$ & $53(3)$ & $1.0 \times 10^{-13}$ & $54(5)$ & $6.7 \times 10^{-15}$ \\
\hline MWS & $151(2)$ & $4.8 \times 10^{-23}$ & $191(4)$ & $4.7 \times 10^{-28}$ \\
\hline
\end{tabular}

Table II. Parameters of the Arrhenius Fits ${ }^{\mathrm{a}}$ of the $\gamma, \beta_{1}, \beta_{2}$ Relaxations and MWS Phenomenon

a Standard deviations are between brackets.
Table III. VFT Parameters of $\alpha$ Relaxation ${ }^{\mathrm{a}}$

\begin{tabular}{lccccc}
\hline \multicolumn{5}{c}{ Water } & \multicolumn{4}{c}{$\alpha_{f}$} \\
Mode & content & $T_{\infty}\left({ }^{\circ} \mathrm{C}\right)$ & $\left(10^{-4} \mathrm{~K}^{-1}\right)$ & $\tau_{\text {Ov }}(\mathrm{s})$ & $D$ \\
\hline$\alpha$ & $1.3 \%$ & $-3(5)$ & $9(1)$ & $5.2 \times 10^{-11}$ & $4.1(0.5)$ \\
& $0 \%$ & $7(3)$ & $6(1)$ & $2.3 \times 10^{-13}$ & $6.0(0.5)$ \\
\hline
\end{tabular}

a Standard deviations are indicated between brackets.

The parameters from Arrhenius behavior for sub-glassy relaxations are reported in Table II.

Various frequencies were investigated in DMA in addition to the previous tests: $10 \mathrm{rad} \mathrm{s}^{-1}$ and $100 \mathrm{rad} \mathrm{s}^{-1}$. In the case of $100 \mathrm{rad}$ $\mathrm{s}^{-1}$, the shift toward higher temperature of the relaxations allows us to observe the $\gamma$ mode. In Figure 5, the mechanical relaxation times were reported. The DMA results are consistent with the law fits, except for the $\gamma$ mode that exhibits a lower relaxation time. These discrepancies can be explained by the solicited groups: DMA transmitted the shear loads, independent from dipole groups while DDS solicitation is function of dipoles in the polymer. ${ }^{40-42}$ Moreover, the $\gamma$ relaxation shifts to higher temperatures after drying. This can be explained by the water evaporation that modified the ethylene sequences environment.

As the sub-glassy relaxations have the same behaviors than the usual PA, we will focus on the $\alpha$ relaxation, as displayed on Figure 6. The parameters from VFT fits are reported in Table III. After drying, the Vogel temperature $T_{\infty}$ increases while the thermal expansion coefficient of the free volume $\alpha_{f}$ decreases.

An intersection of the fit curves can be observed about $116^{\circ} \mathrm{C}$. The fragility index, noted as $D$, was calculated, according to Angell. ${ }^{43,44}$ It is about 4 at $1.3 \%$ water content and 6 after drying. This is the same order of magnitude than the PA $11 .{ }^{45}$

\section{Dynamic Behavior}

A compilation of DSC, DMA, and DDS data has been performed in order to describe the dynamic behavior of PA mXD 10 in a broad temperature and frequency range. For DSC results, an equivalent frequency $f_{\mathrm{eq}}^{\mathrm{DSC}}$ was estimated according to eq. (7). ${ }^{46,47}$

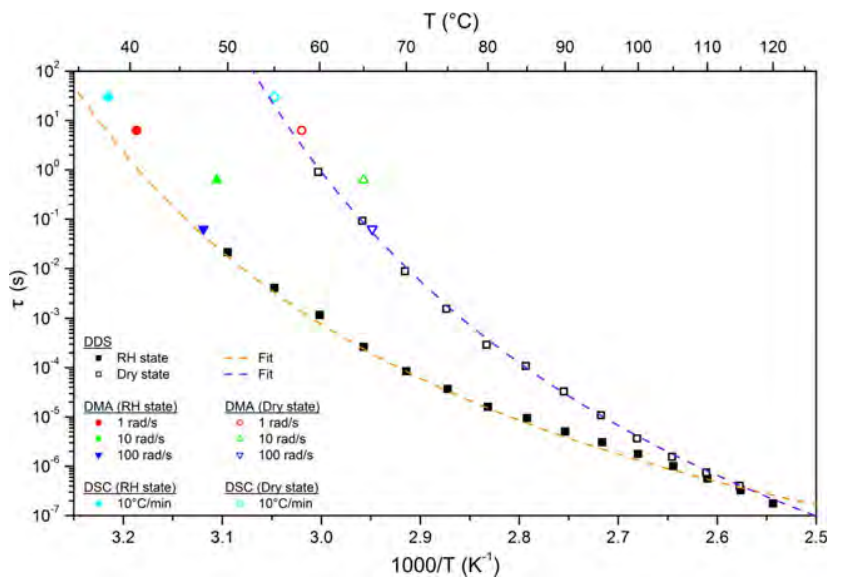

Figure 6. Arrhenius diagram of the $\alpha$ relaxation times and VFT fits (the dashed lines represent the VFT fits). [Color figure can be viewed at wileyonlinelibrary.com] 


$$
f_{\mathrm{eq}}^{\mathrm{DSC}} \approx \frac{q}{2 \pi a \delta T}
$$

where $q$ is the heating rate, $a$ is a constant nearly equal to 1 , and $\delta T$ is the extent of the glass transition.

The equivalent frequency was found around $5.3 \times 10^{-2} \mathrm{~Hz}$. An associated relaxation time $\tau_{\mathrm{eq}}^{\mathrm{DSC}}$ was calculated from eq. (8)

$$
\tau_{\mathrm{eq}}^{\mathrm{DSC}}=\frac{1}{2 \pi f_{\mathrm{eq}}^{\mathrm{DSC}}}
$$

The obtained value is $30 \mathrm{~s}$. This result is consistent with the VFT fit previously determined.

As shown in Figure 6, the results obtained by DSC and DMA are close to the VFT fit determined from the DDS data. Due to the polarity of the polymeric chain, DMA and DDS involve the same molecular entities of PA mXD 10. Moreover, around the glass transition, the chain sequences implied in the $\alpha$ relaxation as shown by DMA and DDS are also involved in the DSC step. An excellent correlation between the different methods is highlighted through the Arrhenius diagram. A precise representation of the molecular mobility at different scales involved in this polymer is proposed. The compilation of these data provides the set of parameters necessary for making prediction of the dynamic mechanical behavior of PA mXD 10 as a function of temperature and frequency.

\section{CONCLUSIONS}

A new grade of bio-based PA-PA mXD 10-was investigated. After saturation at room humidity, the calorimetric study showed a glass transition temperature at $35^{\circ} \mathrm{C}$, two cold crystallizations, and a melting peak at $189{ }^{\circ} \mathrm{C}$. After temperature scans, the $T_{g}$ was stabilized at $55{ }^{\circ} \mathrm{C}$, while the melting peak was unmodified. The $T_{g}$ shift may be explained by the presence, in the initial state, of water that plasticizes the polymer.

By DMA, the mechanical behavior of PA mXD 10 exhibits a storage modulus higher than for PA with analogous aliphatic sequence, such as PA 11. In addition, the value of the storage modulus was nearly constant until room temperature. The $\alpha$ relaxation, related to the mechanical manifestation of the viscoelastic transition, was subjected to the same shift than the glass transition measured by DSC. The localized relaxations $\beta_{1}$ and $\beta_{2}$, respectively, associated with the amide-amide interactions and amide-water interactions exhibited behaviors close to usual PA.

Using DDS, in the low temperature range, the $\gamma$ relaxation, related to the mobility of ethylene sequences, and also $\beta_{1}$ and $\beta_{2}$ relaxations showed Arrhenius behaviors. The $\alpha$ relaxation followed a VFT behavior. The influence of water molecules is also observed on the $\alpha$ relaxation: the Vogel temperature $T_{\infty}$ increased, after drying. All the relaxation times were displayed on an Arrhenius diagram, including the ones determined from DSC and DMA results: this representation allowed us to highlight an excellent correlation between all the methods.

Finally, this study demonstrated that PA mXD 10 fulfills the requirement of mild processing conditions and restricted water uptake. Its specific interest regarding aliphatic PAs like PA 11 is the value of its storage modulus: $1.32 \mathrm{GPa}$. The compilation of thermal, dielectric, and mechanical data allows us to predict the dynamic behavior in a broad frequency and temperature range.

\section{ACKNOWLEDGMENTS}

The authors acknowledge the financial support from Assystem (Toulouse, France) and Association Nationale de la Recherche et de la Technologie (France). They also are grateful to Dr. M. Glotin and Dr. B. Brulé from Arkema for providing PA $\mathrm{mXD} 10$ and for their scientific support.

\section{REFERENCES}

1. Turi, E. Thermal Characterization of Polymeric Materials; Academic Press: San Diego, 1997.

2. Prevorsek, D. C.; Butler, R. H.; Reimschuessel, H. K. J. Polym. Sci. Part A-2: Polym. Phys. 1971, 9, 867.

3. Holmes, D. R.; Bunn, C. W.; Smith, D. J. J. Polym. Sci. 1955, 17, 159.

4. Xenopoulos, A.; Wunderlich, B. J. Polym. Sci. Part B: Polym. Phys. 1990, 28, 2271.

5. Greco, R.; Nicolais, L. Polymer (Guildf) 1976, 17, 1049.

6. Xenopoulos, A.; Wunderlich, B. Polymer (Guildf) 1990, 31, 1260.

7. Füllbrandt, M.; Wellert, S.; Von Klitzing, R.; Schönhals, A. Polymer 2015, 75, 34.

8. Lim, L.; Britt, I. J.; Tung, M. A. J. Appl. Polym. Sci. 1999, $71,197$.

9. Kolařík, J.; Janáček, J. J. Polym. Sci. Part C: Polym. Symp. 2007, 16, 441.

10. Laredo, E.; Hernandez, M. C. J. Polym. Sci. Part B: Polym. Phys. 1997, 35, 2879.

11. Laredo, E.; Grimau, M.; Sanchez, F.; Bello, A. Macromolecules 2003, 36, 9840.

12. Menczel, J. D.; Judovits, L.; Prime, R. B.; Bair, H. E.; Reading, M.; Swier, S. Thermal Analysis of Polymers: Fundamentals and Applications; Wiley: Hoboken, New Jersey, 2009.

13. Li, Y.; Zhu, X.; Tian, G.; Yan, D.; Zhou, E. Polym. Int. 2001, 50, 677.

14. Gogolewski, S. Colloid Polym. Sci. 1979, 257, 811.

15. Ibos, L.; Maraval, C.; Bernès, A.; Teyssèdre, G.; Lacabanne, C.; Wu, S.-L.; Scheinbeim, J. I. J. Polym. Sci. Part B: Polym. Phys. 1999, 37, 715.

16. Neagu, R. M.; Neagu, E.; Kyritsis, A.; Pissis, P. J. Phys. D: Appl. Phys. 2000, 33, 1921.

17. Okamba-Diogo, O.; Richaud, E.; Verdu, J.; Fernagut, F.; Guilment, J.; Fayolle, B. Polym. Degrad. Stab. 2015, 120, 76.

18. Rao, Y.; Waddon, A. J.; Farris, R. J. Polymer (Guildf) 2001, $42,5925$.

19. Lee, Y. S.; Wetzel, E. D.; Wagner, N. J. J. Mater. Sci. 2003, 38, 2825.

20. Cheeseman, B. A.; Bogetti, T. A. Compos. Struct. 2003, 61,161 . 
21. Foo, C. C.; Chai, G. B.; Seah, L. K. Compos. Struct. 2007, 80,588 .

22. Aktay, L.; Johnson, A. F.; Holzapfel, M. Comput. Mater. Sci. 2005, 32, 252.

23. Papaspyrides, C. D.; Porfyris, A. D.; Rulkens, R.; Grolman, E.; Kolkman, A. J. J. Polym. Sci. Part A: Polym. Chem. 2016, 54, 2493.

24. Beaume, F.; Laupretre, F.; Monnerie, L.; Maxwell, A.; Davies, G. R. Polymer (Guildf) 2000, 41, 2677.

25. Cureton, L. T.; Napadensky, E.; Annunziato, C.; La Scala, J. J. J. Appl. Polym. Sci. 2017, 134, DOI: 10.1002/app.45514.

26. Jin, X.; Sun, J.; Zhang, J. S.; Gu, X.; Bourbigot, S.; Li, H.; Tang, W.; Zhang, S. ACS Appl. Mater. Interfaces 2017, 9, 24964.

27. Wang, S.; Wu, X.; Zhang, X.; Niu, H.; Wang, C.; Zhang, Y.; Bai, X.; Wang, W.; Hou, Y. Eur. Polym. J. 2017, 93, 368.

28. Wróblewska, A. A.; Bernaerts, K. V.; De Wildeman, S. M. A. Polymer (Guildf) 2017, 124, 252.

29. Winnacker, M.; Rieger, B. Macromol. Rapid Commun. 2016, 37, 1391.

30. Arkema, B. Brule, P. Bussi, N. Devaux, M. WO 2010/015772 A1 (2010).

31. Wunderlich, B. Kolloid-Zeitschrift Zeitschrift Für Polym. 1969, 231, 605.

32. Chabert, B.; Chauchard, J.; Cinquin, J. Makromol. Chem. Macromol. Symp. 1987, 9, 99.

33. Wunderlich, B. Thermal Analysis of Polymeric Materials; Springer-Verlag: Berlin/Heidelberg, 2005.
34. VanKrevelen, D. W. Properties of Polymers, 2nd ed.; Elsevier, Amsterdam, 1976.

35. McCrum, N. G.; Read, B. E.; Williams, G. An Elastic and Dielectric Effects in Polymeric Solids; Wiley: New-York, 1967.

36. Capsal, J. F.; Pousserot, C.; Dantras, E.; Dandurand, J.; Lacabanne, C. Polymer (Guildf) 2010, 51, 5207.

37. Frank, B.; Frübing, P.; Pissis, P. J. Polym. Sci. Part B: Polym. Phys. 1996, 34, 1853.

38. Carponcin, D. PhD thesis Université De Toulouse III-Paul Sabatier, 2012.

39. Smyth, C. P. Dielectric Behavior and Structure; McGraw-Hill book Company, New York, 1955.

40. Bareš, J. Collect. Czechoslov. Chem. Commun. 1967, 32, 2640.

41. Janáček, J. J. Macromol. Sci. Part C: Polym. Rev. 1973, 9, 3.

42. Hartwig, G. Dielectric Properties and Their Correlations. In: Polymer Properties at Room and Cryogenic Temperatures. The International Cryogenics Monograph Series. Springer, Boston, MA.

43. Angell, C. A. J. Non-Cryst. Solids 1991, 131-133, 13.

44. Bressel, R. D.; Angell, C. A. J. Phys. Chem. 1972, 1086, 3244.

45. Capsal, J.-F. PhD thesis Université De Toulouse III-Paul Sabatier, 2008.

46. Hensel, A.; Dobbertin, J.; Schawe, J. E. K.; Boller, A.; Schick, C. J. Therm. Anal. 1996, 46, 935.

47. Donth, E.-J. Relaxation and Thermodynamics in Polymers: Glass Transition; Akademie Verlag: Berlin, 1994. 